\title{
INFÂNCIA QUILOMBOLA E O PROCESSO DE (IN)VISIBILIDADE: REFLEXÕES NECESSÁRIAS!
}

INFANCIA QUILOMBOLA Y EL PROCESO DE (IN) VISIBILIDAD: ¡REFLEXIONES NECESARIAS!

\section{RESENHA}

Ana Cristina dos Santos Silva Secretaria de Educação de Brumado

MATOS, W. S. de; Benedito E. Etnicidades e Infâncias Quilombolas. Curitiba: Editora CRV, 2019. 98 p.

A escrita do livro "Etnicidades e infâncias quilombolas", de acordo com os autores, emerge discussões acerca da etnicidade, racismo e diversidade em suas múltiplas facetas, mais especificamente direcionado para o contexto educacional em comunidades quilombolas e suas infâncias. A obra reúne os resultados de uma pesquisa qualitativa, do tipo estudo de caso, sobre o processo de configuração do ser quilombola entre um grupo de crianças da comunidade quilombola de Nova Esperança, localizada no município de Wenceslau Guimarães, no Estado da Bahia.

Por meio de um olhar atento e sensível, pautado no rigor cientifico e especialmente na realidade observada in loco, os autores nos trazem, já na apresentação, a premissa de que a Educação Escolar quilombola, mesmo com a aprovação das Diretrizes Curriculares Nacionais para esta modalidade, ainda não vem tendo o devido tratamento por parte dos órgãos que pensam e planejam a educação do país. É, pois, partindo da discussão acerca da invisibilidade da criança quilombola na produção acadêmica que o livro Etnicidades e infâncias quilombolas pretende contribuir para o processo de construção da visibilidade dessas crianças, que

\begin{tabular}{|l|l|l|l|l|l|}
\hline Revista RBBA & ISSN 2316-1205 & Vitória da Conquista & V.8 $\mathrm{n}^{\text {o }} 2$ & p. 221-224 & Dezembro/2019 \\
\hline
\end{tabular}

Recebido em 25 de novembro de 2019. Aprovado em 12 de dezembro de 2019. 
INFÂNCIA QUILOMBOLA E O PROCESSO DE (IN)VISIBILIDADE: REFLEXÕES NECESSÁRIAS!

historicamente foram excluídas das pesquisas e políticas públicas direcionadas à infância brasileira.

Segundo os autores (2019, p.15), a construção da invisibilidade vai adquirindo forma quando o Estado, com seus mecanismos de recenseamento e controle, "uniformiza, em primeira instância, as crianças, em seguida, suas identidades, fazendo desaparecer as especificidades culturais e sociais de cada grupo".

Organizada em três capítulos, os autores trazem no decorrer de suas noventa e sete páginas considerações sobre as comunidades quilombolas, a metodologia empregada na pesquisa e o significado do ser quilombola para um grupo de crianças negras da Comunidade de Nova Esperança.

No primeiro capítulo as discussões giram em torno dos conceitos sobre quilombo e comunidade quilombola, destacando, porém, que o termo quilombola só aparece em documentos oficiais com a Constituição de 1988, fazendo valer os direitos daqueles que sempre foram considerados como seres inferiores, destituídos de direitos fundamentais, numa visão baseada no eurocentrismo. Os autores apontam que inicialmente houve um embate para que se firmasse uma interpretação adequada quanto aos termos remanescentes de comunidades de quilombo ou comunidades remanescentes de quilombos. A primeira interpretação remete à compreensão de um direito individual, enquanto a segunda, corrobora com a perspectiva de um direito coletivo. Santos e Eugenio (2019) evidenciam as discussões em âmbito jurídico e antropológico no processo de definição do artigo 68 do Ato das Disposições Constitucionais Transitórias e suas implicações para a definição dos direitos coletivos dos quilombolas.

No segundo capitulo os autores explicitam a relevância e peculiaridades da pesquisa qualitativa e sua contribuição para a compreensão do processo de construção do reconhecimento como quilombolas de um grupo de crianças. Santos e Eugenio (2019) descrevem a comunidade e apresentam também os instrumentos e procedimentos empregados para a produção dos dados: entrevistas, observação participante e emprego de desenhos confeccionados pelas crianças.

No terceiro e último capítulo, os autores se valem da teoria do reconhecimento proposta pelo filósofo alemão Axel Honneth para traçarem uma abordagem sobre a produção da etnicidade pelas crianças quilombolas da comunidade Nova Esperança. De acordo com os autores, para Honneth, a identidade dos indivíduos está assentada em um processo 


\section{NECESSÁRIAS!}

intersubjetivo conduzido pelo mecanismo de reconhecimento e que este é intrínseco ao ser humano desde o seu nascimento, concretizando-se nas esferas do amor, do direito e da solidariedade.

Utilizando conceitos das esferas do direito e da solidariedade, os autores de Etnicidades e Infâncias Quilombolas apontam que historicamente os quilombolas foram submetidos a situações de desrespeito, direitos negados em relação à igualdade perante e no acesso à justiça e impedidos de alcançar até mesmo dentro do próprio grupo a autoestima. Esse referencial os auxilia ainda a pensar as situações de desrespeito e degradação moral pelas quais as comunidades quilombolas vem enfrentando na contemporaneidade e a emergência por reconhecimento. Conforme os próprios autores nos colocam, essa situação de desrespeito não é algo recente; ao contrário, desde a diáspora africana, essas experiências de desrespeito são vivenciadas através do cerceamento da liberdade e da integridade física. Com a comunidade quilombola de Nova Esperança essa realidade não é diferente, pois ela também pertence a esse coletivo que tem os seus direitos negados pelo Estado.

No último capítulo são apresentados também os dados acerca das concepções das crianças a respeito do ser quilombola e o que a comunidade quilombola de Nova Esperança representava para elas. Para isso, analisam entrevistas e desenhos produzidos por um grupo de crianças. A análise efetuada pelos autores conclui que as crianças se reconhecem etnicamente enquanto quilombolas e que a comunidade é um lugar considerado agradável, principalmente pelo fato de a natureza ser tão marcadamente presente. O fator rural e o camponês são preponderantes nas falas e nos desenhos das crianças, bem mais enfáticos do que a questão de serem quilombolas, que para elas tem correlação com o fato de serem negras. Algumas falas das crianças denotam que elas têm uma consciência racial e um sentimento positivo em relação ao grupo étnico a que pertencem. Os autores constatam que a escola quilombola de Nova Esperança ainda não trabalha com a questão quilombola no currículo praticado na sala de aula.

Há que se destacar a relevância do trabalho desenvolvido pelos autores da obra aqui resenhada, principalmente ao apontarem a invisibilidade das crianças quilombolas no conjunto das pesquisas sobre infâncias realizadas no Brasil. Assim, Etnicidades e infâncias quilombolas é uma leitura indicada a estudantes de licenciatura e estudiosos da infância e das relações étnicas e contribui com o entendimento das relações das crianças quilombolas com seu pertencimento étnico.

Revista RBBA $\mid$ Revista Binacional Brasil Argentina 
INFÂNCIA QUILOMBOLA E O PROCESSO DE (IN)VISIBILIDADE: REFLEXÕES NECESSÁRIAS!

Sobre a autora

Ana Cristina dos Santos Silva possui graduação em Pedagogia pela Universidade do Estado da Bahia (UNEB) e graduação em Ciências Biológicas pela Faculdade Entre Rios, do Piauí (FAERPI). Atualmente é pedagoga na Secretaria de Educação de Brumado/Bahia e Mestranda em Ensino pela Universidade Estadual do Sudoeste da Bahia (UESB).

Endereço eletrônico: anahick2006@hotmail.com 